ISSN 1981-416X

Licenciado sob uma Licença Creative Commons

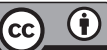

\title{
Processos de ensino e aprendizagem de Matemática em um formato híbrido na educação superior
}

\section{Mathematics teaching and learning processes in a blended learning format in higher education}

\author{
Evandro Antonio Bertoluci ${ }^{[a]}$, Aguinaldo Robinson de Souza ${ }^{[b]^{*}}$ \\ [a] Centro Estadual de Educação Tecnológica Paula Souza (CEETEPS), São Paulo, SP, Brasil \\ [b] Universidade Estadual Paulista (Unesp), São Paulo, SP, Brasil
}

\section{Resumo}

Neste artigo apresentamos os resultados de uma investigação em que buscamos identificar e analisar as contribuições de práticas pedagógicas virtuais e presenciais desenvolvidas por professores mediadores de Matemática de um curso superior de tecnologia da área de Gestão Empresarial, oferecido na modalidade de educação a distância, para a construção de conhecimentos matemáticos pelos alunos. A investigação realizada se enquadrou na vertente qualitativa de pesquisa; buscamos identificar e analisar os processos de ensino e aprendizagem de conteúdos matemáticos, ocorridos no âmbito do curso, em uma turma de um polo de apoio presencial. No referencial teórico consideramos os seguintes tópicos: aspectos da aprendizagem matemática à distância; os ambientes virtuais de 
aprendizagem; as abordagens pedagógicas adotadas em processos formativos; a formatação de cursos em ambientes virtuais; os processos de mediação pedagógica em novos paradigmas; a questão da evasão; os problemas relacionados à gestão, controle e avaliação de cursos a distância e a formação de comunidades de aprendizagem em cursos híbridos. Os resultados indicaram: as contribuições das práticas pedagógicas específicas dos professores mediadores de Matemática do curso para a construção de conhecimentos matemáticos; os diferentes conhecimentos matemáticos construídos pelos alunos, considerando a abordagem pedagógica adotada e as características das tecnologias utilizadas; os fatores que influenciaram a evasão dos alunos ao longo do semestre. Os resultados demonstraram, também: que é de fundamental importância que os professores mediadores tenham formação específica na área ou em áreas afins das disciplinas em que atuam; que os processos de ensino e aprendizagem de Matemática na modalidade de educação a distância podem ser bem-sucedidos se forem adotadas propostas híbridas de educação, com a integração de abordagens e tecnologias presenciais e online, selecionadas de forma minuciosa de tal forma que se complementem.

Palavras-chave: Processos de ensino e aprendizagem. Matemática. Educação a distância. Ensino Híbrido. Educação Superior.

\begin{abstract}
In this article we present the results of an investigation in which we seek to identify and analyze the contributions of virtual and face-to-face pedagogical practices developed by Mathematics mediator's teachers of a superior course of technology of the Business Management area, offered in the modality of distance education, for the construction of mathematical knowledge by students. The research carried out was part of the qualitative aspect of research; we sought to identify and analyze the teaching-learning processes of mathematical contents that occurred within the scope of the course in a class of a face-to-face support center. In the theoretical reference we consider the following topics: aspects of distance learning mathematics; virtual learning environments; the pedagogical approaches adopted in formative processes; the formatting of courses in virtual environments; the processes of pedagogical mediation in new paradigms; the issue of avoidance;
\end{abstract}


the problems related to the management, control and evaluation of distance courses and the formation of learning communities in hybrid courses. The results indicated: the contributions of the specific pedagogical practices of the mathematical mediator's teachers of the course for the construction of mathematical knowledge; the different mathematical knowledge built by the students considering the pedagogical approach adopted and the characteristics of the technologies used; the factors that influenced students' avoidance during the semester. The results also showed: that it is of fundamental importance that mediating teachers have specific training in the area or in related areas of the disciplines in which they work; that the teaching-learning processes of Mathematics in the distance education modality can be successful if hybrid proposals of education are adopted, with the integration of presential and online approaches and technologies, selected in such a way as to complement each other.

Keywords: Teaching-learning processes. Mathematics. Distance Education. Hybrid Education. Higher Education.

\section{Introdução}

A Educação a Distância (EaD) via internet vem apresentando grande crescimento no Brasil e no mundo desde o início do século XXI. Este crescimento está associado, entre outros aspectos, ao desenvolvimento de novas tecnologias de informação e comunicação, especialmente os ambientes virtuais de aprendizagem, ao interesse de instituições de ensino e de propostas governamentais que visam à ampliação do número de cursos e de alunos com nível superior e à legislação, que regulamentou a modalidade de educação a distância oferecendo base legal às propostas de cursos nessa modalidade. Nesse sentido, instituições de ensino superior, públicas e privadas, passaram a oferecer cursos que buscam ampliar o acesso à educação superior.

A expansão da oferta de cursos na modalidade de EaD possibilitou o desenvolvimento de pesquisas e teorizações que abordaram 
diferentes aspectos dessa área temática, entre os quais destacamos: os ambientes virtuais de aprendizagem; as abordagens pedagógicas adotadas em processos formativos; a formatação de cursos nos ambientes virtuais; (MORAN, 2003; 2004; ALMEIDA, 2003; BELLONI, 1999; VALENTE, 2003) os processos de mediação pedagógica em novos paradigmas (MASETTO, 2004; BEHRENS, 2004); a questão da evasão (NETTO; GUIDOTTI; SANTOS, 2012; BITTENCOURT; MERCADO, 2014); os problemas relacionados à gestão, controle e avaliação de cursos desenvolvidos no âmbito da EaD (ROMISZOWSKI, 2012); a formação de comunidades de aprendizagem em cursos híbridos (TORI, 2012; MATHEOS, 2014; VAUGHAN; CLEVELAND-INNES; GARRISON, 2013; VAUGHAN, 2016); entre outros aspectos.

Em relação à área específica da educação matemática envolvendo tecnologias e $\mathrm{EaD}$, os estudos realizados investigaram: a reorganização do pensamento e o papel das mídias em ambientes de aprendizagem online; a atividade docente e o conhecimento profissional em cursos de formação continuada; a aprendizagem colaborativa; a constituição e as características de comunidades virtuais de aprendizagem; a análise dos recursos disponíveis nas plataformas de ensino a distância; a colaboração influenciada pela proposta pedagógica de cursos online; o papel do tutor, as estratégias para o uso da linguagem matemática; a dimensão pedagógico-tecnológica em Matemática da formação profissional docente (PAULIN, 2015); a formação inicial e continuada de professores de Matemática no âmbito da educação a distância (PONTE; OLIVEIRA; VARANDAS, 2003; BORBA; PENTEADO, 2003; BAIRRAL, 2005; BERTOLUCI, 2007; RESENDE; VIEIRA, 2013); entre outros aspectos.

Os estudos realizados no Brasil e em outros países contribuíram para a compreensão de tendências temáticas e/ou aspectos teórico-metodológicos relacionados à EaD de modo geral e à EaD no contexto da educação matemática. Entretanto, as pesquisas realizadas também apontaram a necessidade de novas investigações envolvendo aspectos que ainda não foram bem compreendidos e/ou apresentaram lacunas, dada à complexidade da área de EaD. 
Neste artigo, apresentamos os resultados de uma investigação em que buscamos identificar e analisar as contribuições de práticas pedagógicas, virtuais e presenciais, desenvolvidas por professores mediadores de Matemática no curso superior de Tecnologia da área de Gestão Empresarial, oferecido na modalidade de EaD, para a construção de conhecimentos matemáticos pelos alunos.

\section{Fundamentação Teórica: ambientes virtuais de aprendizagem, abordagens pedagógicas, blended learning e evasão na educação superior a distância}

As discussões sobre a educação a distância, ou mais especificamente, da educação online na educação superior apresentam posicionamentos tanto favoráveis como contrários. Seria, então, viável e/ou apropriada a utilização dessa modalidade de ensino em cursos de graduação que possuem conteúdos matemáticos em suas grades curriculares?

Sabemos que os ambientes virtuais de aprendizagem (AVAs) podem ser utilizados numa perspectiva de construção de conhecimentos pelos graduandos. A especificidade de tais ambientes virtuais pode favorecer a construção de conhecimentos gerais e específicos, discussões em fóruns e chats, interações que possibilitam o intercâmbio de experiências e conhecimentos e envios e recebimentos de materiais didáticos, entre outros aspectos. Como desenvolver, de forma adequada, e considerando a abordagem pedagógica de construção de conhecimentos pelos alunos, o ensino de Matemática na modalidade de EaD? Quais estratégias virtuais de ensino podem ser utilizadas? Que tecnologias ou mídias favorecem ou não o processo de ensino e aprendizagem dos conteúdos da área de Matemática? Que atividades os alunos estão aptos a desenvolver? Quais procedimentos de avaliação podem ser indicados?

Algumas pesquisas mostram a possibilidade de oferta de cursos de formação inicial e continuada de professores de Matemática na modalidade de EaD com elevados padrões qualitativos de formação (PONTE; 
OLIVEIRA; VARANDAS, 2003; BORBA; PENTEADO, 2003; BAIRRAL, 2005; BERTOLUCI, 2007; RESENDE; VIEIRA, 2013). Borba, Malheiros e Amaral (2011) destacaram as possibilidades de educação matemática a distância por meio de chats e de videoconferências. Os autores citados discutiram de forma consistente questões relacionadas aos processos de ensino e de aprendizagem de conteúdos matemáticos em ambientes virtuais.

A pesquisa desenvolvida por Abar e Faria (2015) buscou compreender os componentes presentes nas estratégias adotadas por uma equipe de professores da disciplina de Cálculo, no processo de desenvolvimento de um curso a distância e em que medida tais componentes podem interferir na decisão dos professores na aceitação ou não de inovações no ensino da mesma. Os resultados demonstraram que os componentes presentes nas estratégias dos professores se basearam, em grande parte, nos conhecimentos anteriores e na experiência relacionada aos conhecimentos científicos, pedagógicos e tecnológicos. As autoras apontaram, ainda, a necessidade de ampliação das reflexões sobre o ensino de Matemática na modalidade a distância, principalmente em relação à explicitação dos elementos que contribuam para a superação das dificuldades específicas de área de Matemática em um ambiente de EaD.

Em termos gerais, Moran (2003, p. 39) define a "educação online como o conjunto de ações de ensino e aprendizagem desenvolvidas por meio telemáticos, como a Internet, a videoconferência e a teleconferência" e, aponta as potencialidades dessa modalidade educativa em cursos que vão desde a educação infantil até a pós-graduação. Para ele, novas questões e novos desafios estão surgindo com o avanço da telemática e a utilização de recursos informáticos na criação de cursos online.

Para Almeida (2003), as Tecnologias da Informação e Comunicação (TIC) podem atender a diferentes concepções pedagógicas, ou seja, "podem suportar tanto as tradicionais formas mecanicistas de transmitir conteúdos digitalizados como processos de produção colaborativa de conhecimento". Não há como padronizar nem impor um modelo único de educação online. Cada área do conhecimento deve experimentar, avaliar e avançar na 
construção de propostas pedagógicas adequadas para cada situação de ensino e aprendizagem em ambientes virtuais (MORAN, 2003).

A tendência provável para a educação do futuro - incluindo a educação do professor - aponta para a convergência de dois grandes paradigmas educacionais. O ensino convencional e a educação aberta a distância tendem a diminuir suas diferenças, objetivando a criação de modelos nos quais metodologias e técnicas não presenciais serão utilizadas pelo sistema convencional, e instituições que oferecem cursos a distância passarão a adotar algumas atividades presenciais, conforme as exigências de certas áreas (BELLONI, 1999).

Considerando a tendência de combinar de forma harmoniosa atividades de aprendizagem presencial com atividades desenvolvidas a distância, geralmente online, Tori (2012) apresenta e discute o conceito de blended learning que, segundo o autor, vem se consolidando e apresentando grande potencial na obtenção de resultados educacionais satisfatórios. O autor afirma que está se configurando uma tendência de convergência entre educação virtual e presencial partindo-se dos conceitos de blended learning e de distância em educação. Para o autor,

Com a evolução do blended learning, quebra-se a dicotomia da distância na educação, a qual passa a ser um espectro contínuo, que vai de um nível de proximidade zero (atividade totalmente a distância) à máxima proximidade, em função das dimensões espaço, tempo e interatividade avaliadas sobre as relações aluno/professor, aluno/aluno e aluno/ conteúdo (TORI, 2012, p. 128).

Matheos (2014) considera que a educação híbrida está emergindo como uma das práticas mais promissoras para transformar e sustentar as instituições universitárias canadenses. O conceito de educação híbrida considerado pela autora tem como referência Garrison e Vaughan, citados por Matheos (2014, p. 60), que definem a educação híbrida como "a integração orgânica das abordagens e tecnologias presenciais e online meticulosamente selecionadas e complementares". 
Os resultados de um estudo desenvolvido no Canadá sobre as práticas e barreiras da educação híbrida indicaram: a) uma melhora do ensino e da aprendizagem e aumento do engajamento dos estudantes; b) uma maior flexibilidade para alunos e professores por meio da redução do tempo de sala de aula presencial, substituído por aplicações esclarecidas de aprendizagem online; c) uma satisfação do aluno com o modo híbrido em relação à educação presencial; d) uma melhora do desempenho do estudante, melhores notas nas avaliações, uma menor evasão e diminuição no tempo para conclusão dos estudos; e) uma otimização dos recursos com a incorporação dos materiais online ao ambiente presencial; f) uma confluência de letramentos com a habilitação dos estudantes ao uso de tecnologias essenciais para o mercado de trabalho no mundo contemporâneo (MATHEOS, 2014, p. 62-63).

Vaughan, Cleveland-Innes e Garrison (2013) associam as abordagens híbridas de aprendizagem à constituição de comunidades colaborativas que, com o avanço das tecnologias digitais, principalmente a internet, possibilitam a criação de oportunidades para a interação entre os estudantes, professores e conteúdos. Para Vaughan (2016, p. 57), "a chave é redesenhar cursos híbridos para experiências de aprendizagem ativas e colaborativas que permitam aos estudantes assumirem responsabilidades pela sua aprendizagem e validarem seu entendimento por meio de debates com seus pares".

Behrens (2004) discute a relação entre a era digital e a aprendizagem colaborativa em projetos desenvolvidos em um paradigma emergente, característico da sociedade do conhecimento. Para a autora,

A abordagem pedagógica que valorize a aprendizagem colaborativa depende dos professores e dos gestores da educação, que deverão tornar-se sensíveis aos projetos criativos e desafiadores. Redimensionar a metodologia oferecida dentro da sala de aula demanda contemplar atividades que ultrapassem as paredes das salas, dos laboratórios e dos muros das universidades. As atividades desafiadoras para responder às problemáticas existentes necessitam da criação de espaços virtuais e presenciais dentro e fora da universidade (BEHRENS, 2004, p. 76). 
Por causa da importância de atender a objetivos específicos de um curso ou modalidade de formação a distância via Internet há várias abordagens educacionais que podem ser utilizadas. Valente (2003) apresenta três delas: a Broadcast, a Virtualização da Escola Tradicional e o Estar Junto Virtual, que se diferenciam pelo grau de interação entre o professor e os alunos nas atividades.

$\mathrm{Na}$ abordagem denominada Broadcast, as informações são enviadas aos aprendizes através da Internet, não havendo nenhuma interação entre o emissor (professor) e os receptores (alunos). É um modelo caracterizado pelo tipo de relação um para todos. Virtualização da Escola Tradicional é uma abordagem em que há um mínimo de interação entre o docente e o aprendiz; a relação é de um para poucos. Assemelha-se muito ao que acontece em salas de aula convencionais, nas quais o professor propõe uma tarefa ou uma atividade baseada nos conceitos em estudo e o aprendiz, após a resolução do que foi solicitado, envia sua produção para ser avaliada. A abordagem Estar Junto Virtual, diferentemente das anteriores, se caracteriza por múltiplas e frequentes interações entre o professor e os alunos com vistas a acompanhar a aprendizagem. Nesse tipo de abordagem a ênfase está na construção de conhecimentos pelos aprendizes, com suporte do professor, e não apenas no recebimento de muitas informações que podem, muitas vezes, não serem transformadas em conhecimentos (VALENTE, 2003).

Masetto (2004) destaca a importância da mediação pedagógica associada ao uso de tecnologias na educação superior. $\mathrm{O}$ autor entende a mediação pedagógica como a atitude, o comportamento do professor na condução do processo de ensino e aprendizagem.

É a forma de se apresentar e tratar um conteúdo ou tema que ajuda o aprendiz a coletar informações, relacioná-las, organizá-las, manipulá-las, discuti-las e debatê-las com seus colegas, com o professor e com outras pessoas (interaprendizagem), até chegar a produzir um conhecimento que seja significativo para ele, conhecimento que se incorpore ao seu mundo intelectual e vivencial, e que o ajude a compreender sua realidade humana e social, e mesmo a interferir nela (MASETTO, 2004, p. 145). 
O curso superior de Tecnologia na área de Gestão Empresarial, objeto desta investigação, apresenta uma complexidade própria. O Projeto Pedagógico do curso prevê a utilização inicial de 52 Polos espalhados em 47 municípios do Estado de São Paulo, como locais de encontros presenciais. O Projeto também define os papéis a serem desempenhados pelos professores mediadores presenciais, professores mediadores online, professores responsáveis pelas disciplinas e orientadores de polos. Os polos de apoio presencial se configurarão como locais de suporte aos alunos e de realização das atividades obrigatórias.

O modelo de EaD proposto no curso possibilita o desenvolvimento de pesquisas relevantes. A literatura especializada já apresentou alguns problemas na execução de projetos internacionais de EaD. Dentre os problemas apresentados, destacamos os relacionados à gestão, ao controle e a avaliação inadequados (ROMISZOWSKI, 2012, p. 422-434). Além dos problemas citados por Romiszowski (2012), a evasão em cursos de EaD está se configurando em um problema relevante a ser investigado. Ela pode ser vista sob a ótica da qualidade em EaD e/ou do ponto de vista financeiro das instituições de ensino. Netto, Guidotti e Santos (2012) identificaram os principais motivos para a evasão em EaD: a) questões financeiras, que segundo o estudo se configuram no principal motivo da evasão; b) falta de tempo para a realização das atividades propostas, considerada também com um dos principais motivos da evasão; c) não adaptação ao método de ensino; d) considerar que o método de EaD é mais fácil do que o presencial; e) a obrigatoriedade de realização de provas presenciais.

Em um estudo sobre a evasão no curso a distância de Administração da Universidade Federal de Alagoas/Universidade Aberta do Brasil — UFAL/UAB, Bittencourt e Mercado (2014) constataram que a principal causa da evasão dos alunos esteve relacionada a problemas endógenos diretamente relacionados à instituição de ensino. Os autores apontaram como principais problemas a atitude comportamental, ligada à insatisfação com os tutores e professores, e a motivos institucionais e requisitos didático-pedagógicos, diretamente relacionados a problemas com a plataforma virtual utilizada nos encontros presenciais. Os autores 
sugerem, ainda, a necessidade de formulação de políticas para combater a evasão na educação à distância nas instituições superiores.

\section{Aspectos Metodológicos do Estudo: tipo de pesquisa, formas de coleta e análise dos dados, questão de pesquisa e objetivos}

A investigação realizada se enquadrou na vertente qualitativa de pesquisa, conforme definição de Bogdan \& Biklen (1994). Mais especificamente, a pesquisa buscou identificar e analisar os processos de ensino e aprendizagem de conteúdos matemáticos ocorridos nas práticas pedagógicas virtuais e presenciais de professores de um curso superior de tecnologia da área de Gestão Empresarial em uma turma que pertence a um Polo de apoio presencial. A ênfase se deu nos processos de ensino e de aprendizagem de conteúdos matemáticos abordados na disciplina de Matemática do curso. Foram analisadas as interações de um professor mediador presencial de Matemática e de uma professora mediadora online de Matemática com os alunos participantes da pesquisa.

Coerentemente com a abordagem qualitativa de investigação, o estudo utilizou a análise documental (os documentos relativos Projeto Político Pedagógico do curso, as orientações, comunicações e/ou resoluções definidas pela coordenação do curso, etc.); entrevistas com os professores mediadores e alunos; um questionário enviado por e-mail aos participantes com indagações relacionadas aos objetivos da pesquisa; a análise minuciosa das tecnologias utilizadas para o desenvolvimento do curso, dos registros efetuados no ambiente virtual de aprendizagem, dos materiais instrucionais construídos, das interações estabelecidas, dos critérios de avaliação utilizados; além de outros instrumentos que foram considerados relevantes para a pesquisa.

Em termos mais específicos, fizemos uso de diferentes fontes para a coleta visando uma posterior análise dos dados. Os dados foram coletados de forma objetiva: no Ambiente Virtual de Aprendizagem (AVA) Moodle considerando-se que a maioria dos processos de ensino e aprendizagem de 
Matemática ocorreu nesse ambiente e que ele registrou todas as informações inseridas por professores e alunos, em fóruns de discussão, atividades encaminhadas para avaliação, interações efetuadas etc.; no Projeto Político Pedagógico do curso; através de um questionário enviado por e-mail aos participantes com indagações relacionadas aos objetivos da pesquisa; nos diferentes materiais didáticos construídos (livros digitais, vídeos pedagógicos etc.); e também em outros locais/documentos considerando as necessidades da obtenção de dados durante a realização da pesquisa.

A questão central que norteou o desenvolvimento da pesquisa foi: Quais as contribuições das práticas pedagógicas virtuais e presenciais desenvolvidas por professores mediadores online e presencial de um curso superior de Tecnologia da área de Gestão Empresarial, oferecido na modalidade de educação à distância, para a construção de conhecimentos matemáticos pelos alunos?

O objetivo geral foi identificar e analisar as contribuições das práticas pedagógicas virtuais e presenciais, desenvolvidas por professores mediadores de um curso superior de Tecnologia da área de Gestão Empresarial, oferecido na modalidade de educação à distância, para a construção de conhecimentos matemáticos pelos alunos.

Os objetivos específicos da pesquisa foram identificar e analisar: a concepção pedagógica existente no Projeto Político-Pedagógico do curso a distância de Tecnologia em Gestão Empresarial; as práticas pedagógicas virtuais desenvolvidas pela professora mediadora online e pelo mediador presencial de Matemática; os conhecimentos matemáticos construídos pelos alunos considerando as práticas pedagógicas desenvolvidas pelos professores mediadores, as tecnologias e os materiais didáticos utilizados: livros, vídeos, tarefas etc.; as características das tecnologias de informação e comunicação utilizadas no curso e analisar a coerência entre as tecnologias, a concepção pedagógica, as práticas pedagógicas dos professores mediadores e os materiais didáticos utilizados e, além disso, os fatores que influenciaram a evasão dos alunos ao longo do semestre letivo sob a ótica dos participantes da pesquisa. 


\section{Apresentação, análise e discussão dos resultados da pesquisa}

Os dados coletados para o desenvolvimento da pesquisa referem-se ao primeiro semestre de 2016. Apresentamos, a seguir, os principais resultados obtidos.

O estudo teve a participação de 25 alunos $^{1}$ que cursavam uma graduação tecnológica na área de Gestão Empresarial em um Polo de Apoio Presencial de uma faculdade pública do Estado de São Paulo, Brasil. As práticas pedagógicas específicas envolvendo os conteúdos matemáticos foram desenvolvidas por uma professora mediadora online e por um professor mediador presencial.

A professora mediadora online possuía formação específica em Matemática e mestrado na área de Matemática Aplicada. O professor mediador presencial possuía formação específica em Matemática, mestrado e doutorado em Educação, com área de concentração em Metodologia do Ensino de Matemática. Ambos eram professores contratados por tempo indeterminado da instituição de ensino superior.

Os 25 alunos participantes do estudo residiam em sete municípios que estavam a uma distância média de 28,11 km do Polo de Apoio Presencial, localizado no município de Jahu, SP. A idade média do grupo era de 30-40 anos. Eram 13 mulheres e 12 homens.

Ao longo do semestre letivo, os 25 alunos realizaram atividades avaliativas, atividades não avaliativas e provas presenciais. Foram quatro atividades avaliativas disponibilizadas no AVA e duas provas presenciais obrigatórias, aplicadas no Polo de Apoio Presencial. Para ser aprovado na disciplina Matemática, o aluno precisava alcançar a nota média 6,0 (seis) ou mais. A média aritmética ponderada final da disciplina era calculada

\footnotetext{
${ }^{1} \mathrm{O}$ número de alunos matriculados inicialmente na disciplina era de 64 . Desse número, 20 alunos nunca tinham acessado o AVA até o final de abril de 2016, ou seja, por motivos desconhecimentos não iniciaram a disciplina no semestre letivo. Dos 44 alunos efetivamente matriculados, 25 assinaram o Termo de Consentimento e participaram do estudo. Dos 19 alunos restantes, podemos considerar como evadidos 12 alunos, pois ficaram sem acessar o AVA e realizar as atividades por mais de 30 dias, considerando os dados do final de abril de 2016. A taxa de evasão, portanto, ficou em $27,27 \%$.
} 
considerando a média das notas das atividades avaliativas (com peso de $45 \%$ ) e a média das notas das duas provas presenciais (com peso de 55\%). Ao final do semestre 12 (doze) alunos conseguiram aprovação na disciplina; houve uma grande dispersão das notas médias finais (média de 4,84, desvio padrão de 2,62 e coeficiente de variação de 54,13\%).

Os conteúdos matemáticos das atividades desenvolvidas ao longo do semestre foram divididos em 20 semanas, incluindo duas semanas para as avaliações presenciais obrigatórias (semanas 10 e 20). Os conteúdos matemáticos abordaram: conjuntos e operações; conjuntos numéricos; aritmética e álgebra; funções; lógica proposicional; matrizes; determinantes; sistemas lineares; aplicações de sistemas lineares em problemas empresariais.

Foi possível identificar e analisar a partir dos dados obtidos na pesquisa os conhecimentos matemáticos construídos pelos alunos. No trecho seguinte, o aluno P29² identificou e apresentou os conteúdos matemáticos construídos ao longo do curso, analisou as práticas pedagógicas adotadas, os materiais didáticos utilizados, a importância das atividades avaliativas e não avaliativas, destacou os feedbacks e as vídeo aulas como fundamentais para a sua aprendizagem matemática.

Os conteúdos matemáticos estudados para formação dos meus conhecimentos foram: Conjuntos (parte 1), Conjuntos (parte 2), Operações básicas com conjuntos, Conjuntos Numéricos, Aritmética e Álgebra (parte 1), Aritmética e Álgebra (parte 2), Funções (parte 1), Funções (parte 2), Funções (parte 3), Lógica Proposicional (parte 1), Lógica Proposicional (parte 2), Lógica Proposicional (parte 3), Matrizes, Determinantes, Sistemas, Sistemas Lineares, Operações com Sistemas. Toda a grade mencionada teve em comum como práticas pedagógicas os livros texto e tarefas. Destaque para as tarefas avaliativas que entravam como notas ponderadas na média; não deixando por menos as tarefas não avaliativas, pois, as realizações das mesmas foram um preparo para as avaliações presenciais e um modo de fixar o conteúdo estudado, além do feedback recebido pelo mediador online como forma de tirar dúvidas. Também destaco as vídeo-aulas que foram de grande

${ }^{2}$ Os participantes da pesquisa foram identificados pela letra inicial do seu nome e sua idade. 
valia, uma das práticas pedagógicas com a qual mais me identifiquei como forma de aprendizagem. Além disso, o apoio do mediador online com quem tive contato através de mensagem (P29).

Em outro trecho, quando questionado sobre o que era necessário para aprender Matemática na modalidade de ensino à distância em relação à participação dos alunos, P29 destacou:

É necessário da parte dos alunos, ler o material básico para compreensão dos assuntos e realizar todas as atividades propostas para verificar o grau de aprendizagem que se obteve, pois, a partir desta base as dúvidas surgirão para serem perguntadas através da participação em fóruns de dúvidas, de mensagens para o mediador online ou comparecimento ao polo presencial (P29).

As evidências científicas obtidas nas respostas de $\mathrm{P} 29^{3}$ e dos demais alunos indicaram que o processo de ensino e aprendizagem de Matemática na modalidade de EaD é complexo e sugere a adoção de uma proposta híbrida com a integração de abordagens e tecnologias presenciais e online, selecionadas de forma minuciosa de tal forma que se complementam como afirmam Belloni (1999), Tori (2012), Matheos (2014), Vaughan, Cleveland-Innes e Garrison (2013), Vaughan (2016) e Behrens (2004).

A análise dos dados coletados por meio do questionário também possibilitou a identificação dos principais fatores que influenciaram a evasão dos alunos ao longo do semestre letivo sob a ótica dos participantes da pesquisa.

Os principais fatores identificados que influenciaram a evasão do curso foram: a) falsa expectativa em relação à facilidade do curso; b) falta de conhecimentos matemáticos prévios; c) falta de tempo para a realização das atividades; d) problemas pessoais; e) falta de preparação do aluno para a realização de um curso na modalidade de EaD; f) grau elevado de

\footnotetext{
${ }^{3}$ Todos os alunos que responderam o questionário apontaram a complexidade do processo de ensino e aprendizagem de Matemática à distância e sugeriram a utilização de propostas híbridas de ensino, valorizando as interações online e os encontros presenciais. Alguns alunos, mesmo não tendo participado dos encontros presenciais por diversos motivos, sinalizaram a importância dos momentos presenciais para a aprendizagem matemática.
} 
dificuldade para a realização dos trabalhos e provas; g) falta de vídeos com explicações detalhadas das resoluções dos problemas matemáticos apresentados; h) problemas diretamente relacionados aos mediadores online; i) pouca interatividade no ambiente virtual; j) sensação de solidão; e k) demora de feedback pelo mediador online (NETTO; GUIDOTTI; SANTOS, 2012; BITTENCOURT; MERCADO, 2014).

O Ambiente Virtual de Aprendizagem (AVA) Moodle foi configurado para receber conteúdos durante as 20 semanas do curso. Na Figura 1 apresentamos uma tela do AVA com todos os conteúdos disponibilizados na semana 6 , que continha a primeira atividade avaliativa. A configuração desta e das demais semanas seguiu a seguinte estruturação:

1) Material Básico: link para um vídeo relacionado ao conteúdo da semana; link para um vídeo da professora mediadora online apresentando o conteúdo matemático; e um arquivo no formato PDF com o texto principal relacionado ao conteúdo matemático específico da unidade de aprendizagem.

2) Material Complementar: link para um vídeo complementar relacionado ao conteúdo; um arquivo no formato PDF com texto adicional relacionado ao conteúdo matemático estudado e/ou outras orientações como, por exemplo, informações sobre o uso da calculadora científica na disciplina de Matemática.

3) Atividade Não Avaliativa: um arquivo no formato PDF com o texto da atividade não avaliativa proposta. Após o encerramento do prazo de envio da atividade, um novo arquivo PDF era disponibilizado com o gabarito da atividade, ou seja, as respostas aos exercícios propostos.

4) Atividade Avaliativa: link para o acesso à atividade avaliativa (ferramenta Tarefa do Moodle); um arquivo no formato PDF com a resolução da atividade avaliativa proposta (as respostas corretas) após o encerramento do prazo de envio da atividade avaliativa. 


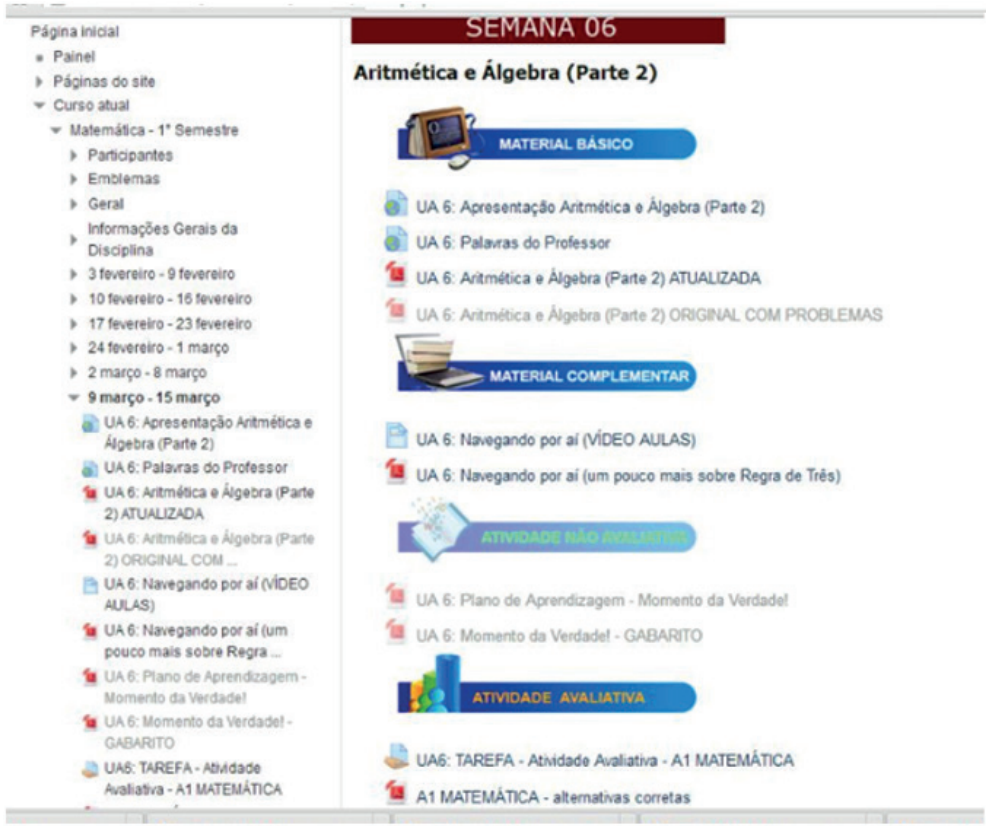

Figura 1 - Configuração da estrutura semanal do AVA - MOODLE.

\section{Contribuições das práticas pedagógicas desenvolvidas pela professora mediadora online para a construção de conhecimentos matemáticos}

Ao longo do semestre, a professora mediadora online de Matemática interagiu com os alunos através do ambiente AVA utilizando diferentes ferramentas digitais (MORAN, 2003; 2004). Foram desenvolvidos Fóruns de Dúvidas relacionados aos conteúdos e disponibilizados vídeos com a apresentação dos conteúdos semanais. Houve também a troca de mensagens entre a professora mediadora online e os alunos e, em algumas situações, orientações sobre a inserção de símbolos matemáticos no editor de texto e sobre as respostas de algumas atividades avaliativas.

Os alunos recebiam feedbacks específicos relacionados às atividades avaliativas. Nestes feedbacks a mediadora online buscava apontar os 
pontos corretos das resoluções e os pontos que mereciam maior atenção como, por exemplo, alguns erros conceituais graves. Podemos inferir desta análise que a professora mediadora online buscou desenvolver uma mediação pedagógica (MASETTO, 2004) voltada para a construção de conhecimentos matemáticos. Os feedbacks oferecidos por ela contribuíram para a construção de conhecimentos matemáticos, pois os alunos poderiam rever as atividades a partir dos apontamentos da mediadora online e depurar os conceitos. A abordagem pedagógica adotada pela mediadora online apresentou algumas características do Estar Junto Virtual (VALENTE, 2003).

Em relação aos Fóruns de Dúvidas, os dados coletados no ambiente AVA indicaram que essa ferramenta de interação foi pouco utilizada pelos alunos, apesar das mensagens postadas pela mediadora online colocando-se à disposição para esclarecimentos de dúvidas conceituais e/ou procedimentais. As estatísticas de utilização do Fórum de Dúvidas mostraram que, nas vinte semanas letivas, ocorreram vinte e três postagens de alunos, resultando em uma média semanal de 1,15 postagens por aluno; avaliamos como um número baixo considerando os vinte e cinco participantes do estudo e a complexidade das atividades. A seguir, apresentamos uma postagem da professora mediadora online, identificada por PROFA. C, dando orientações sobre a utilização do Fórum de Dúvidas.

Durante a leitura do livro-texto ou resolução dos exercícios de Matemática podem surgir dúvidas, é natural que ocorram. O que fazer nessa hora? Você deve postar as suas dúvidas neste espaço! Estou disponível para esclarecer todas elas.

Poste a sua pergunta indicando a Unidade de Aprendizagem (UA) e a sua questão específica (ou número do exercício).

Este é um espaço de interação, assim uma questão proposta por um estudante pode ser respondida ou levada a uma discussão pelos demais estudantes. Sinta-se à vontade para conversar sobre Matemática! Estou à disposição para apoiar e orientar a todos deste polo.

No Fórum de Dúvidas ninguém é avaliado pelas suas postagens. Apenas mantenha o foco no conteúdo específico de Matemática, para 
termos bom aproveitamento do espaço. Perceba que há vários recursos disponíveis para comunicação. Você pode: redigir um texto; anexar um arquivo (em Word, por exemplo); postar links da internet, inclusive para vídeo; postar imagens/figuras, dentre outras possibilidades. Bem, aproveite tudo isso! Acesse esse espaço com frequência. Aguardo por todos. Até breve! (PROFA. C).

Os trechos seguintes, considerados representativos das interações e das contribuições das práticas pedagógicas virtuais, ilustram bem algumas mensagens trocadas através da ferramenta Fórum de Dúvidas entre a professora mediadora online e alguns alunos. É possível identificar que os conteúdos das mensagens foram variados, e abordaram as dúvidas sobre o envio de atividades não avaliativas, os retornos de mensagens pela mediadora online, as orientações dadas pela mediadora online a respeito de atividades avaliativas (prazos, conteúdos etc.), além de outros esclarecimentos matemáticos sobre a resolução de atividades que apresentavam alguns erros.

Nos excertos seguintes podemos perceber que a professora $C$ orientou a aluna A44 sobre quais atividades deveriam ser enviadas para correção e forneceu informações aos alunos sobre a segunda atividade avaliativa:

Olá, A44. As atividades não avaliativas não devem ser enviadas. Elas são importantes para você exercitar os conceitos da UA. Você deve enviar para correção somente as atividades que constarem em Atividade Avaliativa. Nesta semana 13 temos uma sobre Lógica, dê uma olhada. Um abraço (PROFA. C).

Caro (a) estudante. A segunda atividade avaliativa de Matemática ficará aberta para envio no período de 27/04 a 10/05. Para realizá-la você deve utilizar os conceitos de Lógica Proposicional estudados nas UA 11, 12 E [sic] 13. Leiam atentamente o enunciado e sigam as orientações fornecidas. Estou disponível neste espaço para esclarecer eventuais dúvidas que surgirem na execução da atividade. Grande abraço (PROFA. C).

Em outra mensagem postada no Fórum de Dúvidas, a professora $C$ forneceu informações sobre a terceira atividade avaliativa e se colocou à disposição para eventuais esclarecimentos de dúvidas. 
Olá, pessoal. Tudo bem? Nesta semana 16 disponibilizamos a terceira atividade avaliativa de Matemática que é um Questionário online. É muito importante que você saiba que: esta atividade ficará aberta para envio no período de 18/05 a 31/05. Não haverá prorrogação de prazo; você tem 50 minutos para realizá-la. Aproveite este tempo; você tem apenas uma tentativa, não acesse o questionário se não for para realizar a atividade. Não haverá nova possibilidade de tentativa. É fundamental que: você leia as orientações disponíveis na ferramenta da atividade antes de começar o questionário. Estou disponível no Fórum de Dúvidas para esclarecer eventuais dúvidas que surgirem para realização da atividade. Sucesso a todos! (PROFA. C).

A professora $C$, em outra postagem no Fórum de Dúvidas, orientou a aluna P36 sobre as provas, sobre os conteúdos matemáticos que seriam avaliados e sobre o material complementar que a aluna poderia utilizar para estudar o conteúdo matemático da semana. A professora C também se colocou à disposição para esclarecimentos de dúvidas pelo Fórum e indicou o mediador presencial de Matemática do Polo.

Olá, P36. 1) A nota da prova P2 tem peso maior que a da P1 no cálculo da média final, e a P2 ainda não aconteceu. 2) Há uma atividade avaliativa aberta na semana 18 , você deve caprichar na sua realização. 3) Conforme você cita: o Prof. E escreveu que "Haverá prova substitutiva para repor prova não realizada ou nota baixa da semana 10". Isso quer dizer que, se você quiser fazer a prova substitutiva para substituir a nota da P1, você pode. É uma oportunidade de melhorar seu desempenho. Esta prova acontece na semana 21 e envolve toda a matéria do semestre. A data deve ser conferida no calendário do seu polo. Realizando a substitutiva você pode tirar nota maior que 3,5 e melhorar sua média. 4) Em "Material Complementar" disponibilizamos vídeo aulas sobre o conteúdo da semana que tem ajudado muito aos alunos a compreender a matéria da semana. Você está assistindo a essas vídeo aulas? 5) Eu estou disponível aqui no Fórum de Dúvidas para lhe ajudar nos conteúdos. Basta postar sua dúvida ou dificuldade e eu lhe ajudarei. 6) Há mediador presencial de Matemática no seu polo, que é o Prof. E, e pode lhe ajudar com o conteúdo de Matemática. Você precisa verificar o horário de atendimento que ele disponibiliza 
no polo. Para ter essa informação, você pode ligar no polo ou entrar em contato com ele via AVA [...] (PROFA. C).

No trecho seguinte, a professora $C$ fez a mediação online sobre um conteúdo matemático específico: o processo de resolução de sistemas lineares por escalonamento. Ela apontou a aplicabilidade da técnica de escalonamento para a resolução de sistemas lineares, fez referência à classificação dos sistemas lineares e indicou dois erros cometidos pela aluna P36. A professora $C$ percebeu que a aluna estava progredindo na construção de seus conhecimentos sobre o tema de sistemas lineares.

Olá P36. Parabéns pela sua dedicação. Você está no caminho certo! Este método também é escalonamento, pode ser utilizado sem problema. Você deve prestar atenção ao seguinte: um sistema linear pode ter uma única solução, ter infinitas soluções ou não ter solução. Nem sempre se chega a valores únicos para as incógnitas! Você cometeu apenas dois pequenos equívocos na sua resolução. $\mathrm{O}$ primeiro foi trocar um sinal no sistema inicial: veja no enunciado que o número que acompanha o $\mathrm{z}$ na terceira equação é +2 e não -2 como você colocou. $\mathrm{O}$ segundo foi nesta equação: Resultado

$0+5 y+5 z=12$ (multipliquei por -1 )

$0+5 y+5 z=18$ (somei)

Como você trocou um número no início, deve acertar e conferir todo o processo. Percebo que você entendeu bem o que foi proposto, basta um ajuste para finalizar. Não esqueça de classificar o sistema e apresentar a solução (PROFA. C).

Os trechos seguintes ilustram algumas interações virtuais efetuadas entre a professora $C$ e o aluno A28. É possível perceber que a professora buscou conhecer as dúvidas do aluno e desenvolver tanto uma mediação online como uma presença virtual (MASETTO, 2004; VALENTE, 2003) específica para a aprendizagem matemática de conjuntos numéricos e suas operações. No final, a professora fez indicação de vídeos relacionados aos conteúdos estudados. 
Oi A28. Você poderia dar um exemplo de um exercício que resolveu e a resposta não está de acordo, para eu verificar? Você pode explicar como resolveu OK? Aguardo seu retorno (PROFA. C).

Determine $A$ inter $B$ e $A$ união $B$ para os intervalos a seguir: $A=[3,9]$ e $B=$ $[6,11]$. Minha resposta: $A$ inter $B=$ vazio. $A$ união $B=[3,6,9,11]$. Resposta no Momento da Verdade: $A$ inter $B=[6,9]$ e $A$ união $B=[3,11]$ (A28).

Bom dia! Inicialmente, observe que estamos usando colchetes para representar A e B. Os colchetes indicam intervalos de números reais. Perceba que $[3,9]$ é diferente de $\{3,9\}$. Quando usamos as chaves $\{\ldots\}$, indicamos exatamente os elementos listados. No caso: $\{3,9\}$ é o conjunto formado exatamente pelos elementos 3 e 9. Quando usamos colchetes [...], indicamos todos os números reais que estão no intervalor. No caso, no intervalo $[3,9]$ há infinitos números reais. Aí estão todos os números reais entre 3 e 9, incluindo o 3 e o 9. [...] A mesma ideia vale para o intervalo B. Assim, a interseção de A e B não é o conjunto vazio. $\mathrm{Na}$ intersecção estão todos os números entre 6 e 9 , incluindo o 6 e o 9. Ou seja, qualquer número real maior ou igual a 6 e menor ou igual a 9 pertence tanto a $\mathrm{A}$ quanto a $\mathrm{B}$. Portanto: $\mathrm{A}$ inter $\mathrm{B}=[6$, 9]. No caso da União de A e B, devemos reunir todos os números que estão em $\mathrm{A}$ e em $\mathrm{B}$. Logo, na união teremos todos os números maiores ou igual a 3 e menores ou igual a 11 . Ou seja: $A$ união $B=[3,11]$. Veja que usamos os colchetes (pois temos intervalos de números reais) (PROFA. C).

Oi, A28.

As vídeo aulas [sic] a seguir fornecem explicações detalhadas relativas à representação de intervalos reais, união, interseção de intervalos. Vão lhe ajudar. Abraços. Profa. C (PROFA. C).

\section{Contribuições das práticas pedagógicas desenvolvidas pelo professor mediador presencial para a construção de conhecimentos matemáticos}

Ao longo do semestre o professor mediador presencial de Matemática interagiu com os alunos de forma predominante no Polo de Apoio 
Presencial ${ }^{4}$. Eventualmente havia alguma interação através do ambiente AVA como, por exemplo, com trocas de mensagens e nos momentos dos feedbacks das provas presenciais, nos quais o professor mediador presencial inseria no ambiente AVA as notas e os comentários relacionados às questões resolvidas de forma correta e incorreta. Os feedbacks das provas podem ser considerados momentos importantes da prática pedagógica do professor mediador presencial. Nos feedbacks o mediador presencial contribuía para a aprendizagem matemática dos alunos comentando as questões resolvidas, apontando os erros conceituais e/ou procedimentais, indicando a forma adequada de resolução dos exercícios e/ou problemas, destacando as resoluções corretas e incentivando os alunos na realização das atividades de cunho matemático.

Em relação aos atendimentos oferecidos aos alunos no Polo de Apoio Presencial pelo mediador presencial de Matemática, observamos que houve uma baixa frequência de visita dos alunos ao Polo: uma média $20 \%$ dos participantes frequentou o Polo regularmente. A frequência de visita aumentava um pouco, para $25 \%$, quando o mediador presencial convidava os alunos para "Oficinas de Matemática", nas quais os conteúdos das unidades de aprendizagem eram revistos de forma presencial. Nas respostas dadas ao questionário ${ }^{5}$, os encontros presenciais no Polo foram considerados muito significativos, essenciais, para a aprendizagem matemática. Nesse ponto, os resultados obtidos são semelhantes aos encontrados por Resende e Vieira (2013) nos quais os entrevistados consideravam de fundamental importância a realização de encontros presenciais para a aprendizagem matemática.

Os trechos seguintes são considerados representativos das contribuições das práticas pedagógicas desenvolvidas pelo professor

4 O professor mediador presencial tinha um horário de permanência no Polo de Apoio Presencial para atender os alunos, ou seja, ficava à disposição dos alunos por duas aulas semanais. A presença dos alunos no Polo era facultativa; quando necessitavam de esclarecimentos específicos de conteúdos matemáticos, os alunos se dirigiam ao Polo e recebiam atendimentos individuais e/ou em grupos.

5 Para $82 \%$ dos alunos que responderam o questionário, os encontros presenciais foram essenciais para a aprendizagem matemática. Os $18 \%$ restantes indicaram que não houve necessidade de comparecimento ao Polo de Apoio Presencial para esclarecimentos de dúvidas. 
mediador presencial, para a construção de conhecimentos matemáticos pelos alunos. É possível identificar nos excertos que o professor mediador presencial de Matemática contribuiu de forma significativa para a construção de conhecimentos matemáticos. O material disponibilizado era satisfatório, mas existia a necessidade de momentos presenciais para a compreensão dos conteúdos matemáticos. Observamos uma preferência dos alunos pelas interações presenciais em relação às interações online, pois expressar dúvidas por mensagens digitais era mais difícil e, durante as interações presenciais, as dúvidas poderiam ser sanadas de forma específica.

No excerto seguinte, a aluna P36 destaca a importância da explicação recebida no Polo pelo professor mediador presencial, identificado por Prof. E, para a construção do conhecimento envolvendo sistemas de equações lineares.

Fui ao polo, revi todo o material, passei o domingo somente no exercício [...]. Vi que a apostila e os sites da internet do material complementar fazem por meio de matrizes, mas o Prof. E no Polo ensinou de um jeito que parecia mais fácil, ou pelo menos eu entendi melhor, enfim, segue a forma que aprendi com ele, mas que na apostila é similar (P36).

A aluna A44 também considerou importantes as atividades presenciais desenvolvidas pelo mediador presencial para a aprendizagem matemática, como podemos visualizar no texto abaixo:

Por ter cursado a disciplina Matemática no primeiro semestre, entendo que os conteúdos apresentados são muito bons, mas no meu caso, precisei de apoio prático e fui buscá-lo tanto na Fatec, quanto com pessoas que estão cursando outras áreas, pois somente com o material apresentado não consegui desenvolver todo o raciocínio necessário, até pela falta de base do ensino médio [...] Sim, como citei acima, compareci ao polo, e a ajuda do mediador presencial foi essencial (A44).

Em outro trecho, ao responder sobre as características das interações com os mediadores, a aluna A44 destacou que realizou interações somente com o mediador presencial e que essas interações contribuíram 
para a construção de seus conhecimentos matemáticos. A aluna também sugere a realização de mais encontros presenciais no polo, pois os encontros contribuem para esclarecer vários aspectos do curso.

Não interagi com o mediador online, somente com o professor mediador presencial. No auxílio presencial, o professor apresentou as matérias de forma prática, e sempre reforçando a parte teórica, e foi o que fez a diferença [...] Acredito que o material disponibilizado atende às necessidades, mas precisa ser melhor trabalhado pelos alunos - por isso, minha sugestão é que haja mais encontros presenciais no Polo, para divulgação dos recursos (A44).

A aluna A39 destacou a importância das práticas pedagógicas desenvolvidas pelo professor mediador presencial para a construção de seus conhecimentos matemáticos. Há evidências na resposta de A39 que o professor mediador presencial de Matemática desenvolveu uma mediação pedagógica na perspectiva apontada por Masetto (2004).

O mediador presencial de Matemática foi de extrema importância para o meu aprendizado, uma vez que, quando do surgimento de alguma dúvida, eu preferia procurá-lo no polo por ser mais rápido e prático e suas explicações serem muito claras, simples e de fácil entendimento, sem falar da prontidão em nos atender no que diz respeito ao aprendizado da disciplina. Também sempre se colocou à disposição para nos auxiliar em revisões nas semanas antes da prova, o que fez uma enorme diferença na hora da realização da mesma. Eu comparecia frequentemente ao polo, foi o que me ajudou muito a assimilar o conteúdo disponibilizado para estudo (A39).

Ao responder sobre as características das interações com os mediadores, a estudante A39 apresentou sua preferência pelos encontros presenciais para a aprendizagem matemática. Essa resposta sugere a importância das abordagens híbridas de cursos, como indicam Belloni (1999), Tori (2012), Matheos (2014), Vaughan, Cleveland-Innes e Garrison (2013) e Behrens (2004). 
A interação com o mediador online é mais complicada se considerado o fato de que a resposta às nossas perguntas pode demorar alguns dias, e que, nem sempre conseguimos expressar corretamente nossas dúvidas, através de mensagens, para que o mesmo possa nos auxiliar. Já o mediador presencial nos auxilia no momento da dúvida, exemplificando e resolvendo o exercício de maneira que você aprenda corretamente como se faz, identificando e indicando possíveis erros na hora da resolução do exercício. No meu caso eu aprendo melhor com o mediador presencial, uma vez que as dúvidas são esclarecidas imediatamente e é dispensada muita teoria que faz com que eu me perca no entendimento (A39).

Um posicionamento semelhante ao da aluna A39 foi apresentado pela aluna G31. Para essa aluna, os encontros presenciais foram considerados essenciais para a sua aprendizagem matemática.

Quando tinha muitas dúvidas (o que não era difícil) geralmente ia ao polo aprender. Isso me ajudou muito! Fui muito bem recebida e tive ótimas explicações. Consegui terminar a disciplina através desses encontros presenciais. O professor explicava de um modo mais fácil de aprendermos. Para mim a forma mais efetiva para aprender matemática foi com o mediador presencial. Fui várias vezes ao polo tirar dúvidas, não fui mais devido a carga horária de trabalho. Geralmente ele perguntava quais eram minhas dificuldades e com uma boa conversa, ele já via onde estava errando e me explicava, fazia exercícios comigo, me explicando como resolvê-los. Dava muitas dicas de como fazer e estudar a matéria. Foi ótimo para que eu aprendesse (G31).

O aluno M29 destacou a importância dos momentos presenciais para a sua aprendizagem matemática. Para esse aluno, foram as interações/explicações com/do mediador presencial que contribuíram de forma significativa para a construção de seus conhecimentos matemáticos.

Sim, compareci ao polo, e foi o que realmente me tirou as dúvidas e me fez compreender a matéria, foi essencial para o meu aprendizado. [...] o mediador presencial, o professor explicou detalhadamente a forma de fazer os exercícios e de forma paciente, o que resultou na minha melhora na matéria de Matemática (M29). 


\section{Considerações finais}

Os dados coletados e analisados, considerando a questão de pesquisa, os objetivos do estudo e os apontamentos dos referenciais teóricos, possibilitaram a elaboração de reflexões a respeito de práticas pedagógicas virtuais e presenciais desenvolvidas por professores mediadores de Matemática, em um curso superior de tecnologia, oferecido na modalidade de EaD via internet.

Foi possível identificar e analisar: a) as contribuições das práticas pedagógicas específicas dos professores mediadores de Matemática do curso para a construção de conhecimentos matemáticos pelos alunos; b) os conhecimentos matemáticos construídos pelos alunos considerando a abordagem pedagógica adotada e as características das tecnologias utilizadas; c) os fatores que influenciaram a evasão dos alunos ao longo do semestre letivo sob a ótica dos participantes da pesquisa; e d) outros aspectos relacionados ao curso.

Em relação às práticas pedagógicas desenvolvidas pelos mediadores, percebemos que elas contribuíram de forma diferenciada para as aprendizagens matemáticas dos alunos, como discutido ao longo do presente texto. De forma geral, os dois professores mediadores buscaram desenvolver mediações pedagógicas (MASETTO, 2004) na perspectiva de construção de conhecimentos matemáticos por parte dos alunos, cada um atuando em seu espaço específico, ou seja, no virtual e no presencial. Evidentemente, interações entre os mediadores que atuavam nos dois ambientes ocorreram; tais interações são, inclusive, indicadas, considerando a complexidade do modelo de curso e as especificidades dos conteúdos matemáticos.

Um ponto que merece ser destacado está relacionado à formação dos professores mediadores para atuação em uma determinada disciplina em um curso a distância. É de fundamental importância que os professores mediadores tenham formação específica na área ou em áreas afins das disciplinas em que atuam. No caso específico do curso em análise, ambos os mediadores possuíam formação na área de Matemática; os resultados obtidos em relação às aprendizagens matemáticas dos alunos certamente tiveram relação com a formação, os conhecimentos e a experiência dos mediadores. Preocupa-nos a tendência de algumas instituições de ensino 
superior em utilizar mediadores e/ou tutores em cursos a distância que não tenham formação específica nas disciplinas em que atuarão. Práticas de gestão dessa natureza comprometem e podem afetar negativamente a qualidade da formação oferecida aos alunos.

Outra consideração importante está relacionada aos conhecimentos matemáticos construídos ao longo do curso pelos alunos. Os dados sinalizaram que é possível ensinar e aprender Matemática em um curso a distância com as características descritas neste estudo. A construção de conhecimentos matemáticos em um curso a distância está diretamente relacionada, dentre outros aspectos, às abordagens pedagógicas do curso, às práticas pedagógicas adotadas pelos mediadores, aos materiais didáticos disponibilizados, às tecnologias utilizadas e às posturas dos alunos.

Os resultados da pesquisa evidenciaram que os processos de ensino e aprendizagem de Matemática, na modalidade de EaD, podem ser bem-sucedidos se forem adotadas abordagens híbridas de ensino, com a integração de abordagens e tecnologias presenciais e online, selecionadas de forma minuciosa de tal forma que se complementem, como indicam Belloni (1999), Tori (2012), Matheos (2014), Vaughan, Cleveland-Innes e Garrison (2013), Vaughan (2016) e Behrens (2004).

As aprendizagens matemáticas alcançadas pelos alunos participantes da pesquisa poderiam ter sido mais significativas se as interações entre todos os envolvidos no curso (alunos e mediadores) tivessem sido mais frequentes, como, por exemplo, a formação de uma comunidade de aprendizagem (VAUGHAN; CLEVELAND-INNES; GARRISON, 2013). Um dos principais desafios de propostas híbridas de cursos (atividades desenvolvidas nos formatos online e presencial), consideradas por nós apropriadas para processos de ensino e aprendizagem de Matemática no âmbito da $\mathrm{EaD}$, é encontrar formas de unir práticas de ensino presenciais e práticas de ensino à distância com a maximização da participação e interação entre os alunos e os professores mediadores. As propostas híbridas de um determinado curso devem possibilitar experiências ativas e colaborativas de aprendizagem, nas quais os alunos assumam o compromisso 
pela construção de seus conhecimentos (VAUGHAN, 2016) com o uso de diferentes recursos tecnológicos e humanos.

Em relação aos principais fatores relacionados à evasão dos alunos do curso, as respostas indicaram pontos já apresentados pela literatura de EaD (NETTO; GUIDOTTI; SANTOS, 2012; BITTENCOURT; MERCADO, 2014), dentre os quais destacamos: a falsa expectativa em relação à facilidade do curso; a falta de conhecimentos matemáticos prévios; a falta de tempo para a realização das atividades; os problemas pessoais; o grau elevado de dificuldade das atividades; a falta de vídeos com explicações específicas de conteúdos matemáticos; os problemas com o mediador online; e, por fim, a pouca interatividade realizada no ambiente virtual de aprendizagem.

A adoção do modelo de ensino híbrido, com as características apresentadas por Belloni (1999), Tori (2012), Matheos (2014), Vaughan, Cleveland-Innes e Garrison (2013), Vaughan (2016) e Behrens (2004), poderia contribuir para minimizar as principais causas da evasão no curso. Um modelo de ensino híbrido pode contribuir para aumentar o engajamento dos alunos no curso; apresentar uma maior flexibilidade nas aulas, com atividades realizadas no ambiente virtual e no polo de apoio presencial; aumentar a satisfação dos alunos em relação ao curso e às ferramentas digitais utilizadas; e melhorar os processos de ensino e aprendizagem de Matemática.

Os resultados apresentados contribuem de forma consistente para a ampliação dos conhecimentos relacionados aos processos de ensino e aprendizagem de Matemática no contexto da $\mathrm{EaD}$ via internet. Entretanto, novos estudos são necessários, com a investigação de outros aspectos relacionados à educação matemática no âmbito da EaD como, por exemplo, a avaliação da aprendizagem matemática, principalmente em um momento de expansão de cursos oferecidos nessa modalidade de ensino. 


\section{Referências}

ABAR, C. A. A. P.; FARIA, E. C. A inovação na prática de professores de matemática no ensino a distância. In: ROSA, M.; BAIRRAL, M. A.; AMARAL, R. B. (Org.). Educação matemática, tecnologias digitais e educação a distância: pesquisas contemporâneas. São Paulo: Editora Livraria da Física, 2015. p. 263-309.

ALMEIDA, M. E. B. Educação, ambientes virtuais e interatividade. In: SILVA. M. (Org.). Educação Online. São Paulo: Edições Loyola, 2003. p. 201-215.

BAIRRAL, M. A. Desenvolvendo-se criticamente em matemática: a formação continuada em ambientes virtualizados. In: FIORENTINI, D.; NACARATO, A. M. (Org.). Cultura, formação e desenvolvimento profissional de professores que ensinam matemática: investigando e teorizando a partir da prática. São Paulo: Musa, 2005. p. 49-67.

BELLONI, M. L. Educação a distância. Campinas: Autores Associados, 1999.

BEHRENS, M. A. Projetos de aprendizagem colaborativa num paradigma emergente. In: MORAN, J. M.; MASETTO, M. T.; BEHRENS, M. A. Novas tecnologias e mediação pedagógica. 8. ed. Campinas: Papirus, 2004. p. 67-132.

BERTOLUCI, E. A. Formação continuada online de professores dos anos iniciais: contribuições para a ampliação da base de conhecimento para o ensino de Geometria. 2007. 385 f. Tese (Doutorado em Educação) - Centro de Educação e Ciências Humanas, Universidade Federal de São Carlos, São Carlos, 2007.

BITTENCOURT, I. M.; MERCADO, L. P. L. Evasão nos cursos na modalidade de educação a distância: estudo de caso do Curso Piloto de Administração da UFAL/ UAB. Ensaio: avaliação, políticas públicas e Educação, Rio de Janeiro, v. 22, n. 83, p. 465-504, abr./jun. 2014.

BOGDAN, R. C.; BIKLEN, S. K. Investigação Qualitativa em Educação: uma introdução à teoria e aos métodos. Portugal: Porto Editora, 1994.

BORBA, M. C.; MALHEIROS, A. P. S.; AMARAL, R. B. Educação a distância online. 3. ed. Belo Horizonte: Autêntica Editora, 2011. 
BORBA, M. C.; PENTEADO, M. G. Informática e Educação Matemática. 3. ed. Belo Horizonte: Autêntica, 2003.

MASETTO, M. T. Mediação pedagógica e o uso da tecnologia. In: MORAN, J. M.; MASETTO, M. T.; BEHRENS, M. A. Novas tecnologias e mediação pedagógica. 8. ed. Campinas: Papirus, 2004. p. 133-173.

MATHEOS, K. Educação híbrida: a chave da inovação nas universidades canadenses. In: REALI, A. M. M. R.; MILL, D. R. S. (Org.). Educação a Distância e tecnologias digitais: reflexões sobre sujeitos, saberes, contextos e processos. São Carlos: EdUFSCar, 2014, p. 57-68.

MORAN, J. M. Contribuições para uma pedagogia da educação online. In: SILVA, M. (Org). Educação Online. São Paulo: Edições Loyola, 2003. p. 39-50.

MORAN, J. M. Ensino e aprendizagem inovadores com tecnologias audiovisuais e telemáticas. In: MORAN, J. M.; MASETTO, M. T.; BEHRENS, M. A. Novas tecnologias e mediação pedagógica. 8. ed. Campinas: Papirus, 2004. p. 11-65.

NETTO, C.; GUIDOTTI, V.; SANTOS, P. K. A evasão na EaD: investigando causas, propondo estratégias. In: CONFERÊNCIA LATINOAMERICANA SOBRE EL ABANDONO EM LA EDUCACIÓN SUPERIOR, 2., 2012. Porto Alegre. Anais... Pontifícia Universidade Católica do Rio Grande do Sul, Porto Alegre, 2012.

PAULIN, J. F. V. Educação matemática, tecnologias digitais e educação a distância: um olhar retrospectivo para os artigos do SIPEM. In: ROSA, M.; BAIRRAL, M. A.; AMARAL, R. B. (Org.). Educação matemática, tecnologias digitais e educação a distância: pesquisas contemporâneas. São Paulo: Editora Livraria da Física, 2015. p. 17-56.

PONTE, J. P.; OLIVEIRA, H.; VARANDAS, J. M. O contributo das tecnologias de informação e comunicação para o desenvolvimento do conhecimento e da identidade profissional. In: FIORENTINI, D. (Org.). Formação de professores de Matemática: explorando novos caminhos com outros olhares. Campinas: Mercado de Letras, 2003. p. 159-192. 
RESENDE, M. R.; VIEIRA, V. M. O. Formação do professor de Matemática na modalidade a distância: o que pensam os alunos sobre sua aprendizagem. Rev. Diálogo Educ., Curitiba, v. 13, n. 38, p. 161-182, jan./abr. 2013.

ROMISZOWSKI, A. J. Aspectos da pesquisa em EAD. In: LITTO, F. M.; FORMIGA, M. (Org.). Educação a Distância: o estado da arte. 5. imp. São Paulo: Pearson Education do Brasil, 2012. p. 422-434.

TORI, R. Cursos híbridos ou blended learning. In: LITTO, F. M.; FORMIGA, M. (Org.). Educação a Distância: o estado da arte. 5. imp. São Paulo: Pearson Education do Brasil, 2012. p. 121-128.

VALENTE, J. A. Curso de Especialização em Desenvolvimento de Projetos Pedagógicos com o Uso das Novas Tecnologias: Descrição e Fundamentos. In: VALENTE, J. A.; PRADO, M. E. B. B.; ALMEIDA, M. E. B. (Org.). Educação a Distância Via Internet. São Paulo: Avercamp, 2003. p. 23-56.

VAUGHAN, N. D.; CLEVELAND-INNES, M.; GARRISON, D. R. Teaching in Blended Learning Environments: creating and sustaining communities of inquiry. Athabasca University: AU Press, 2013.

VAUGHAN, N. D. Qualidade na educação: convergência de sujeitos, conhecimentos, práticas e tecnologias. In: MILL, D. R. S.; REALI, A. M. M. R. (Org.). Educação a distância, qualidade e convergências: sujeitos, conhecimentos, práticas e tecnologias. São Carlos: EdUFSCar, 2016. p. 37- 59.

Recebido: 30/04/2018

Received: 04/30/2018

Aprovado: $20 / 05 / 2018$ Approved: 05/20/2018 